\title{
Effects of Butyrate on the Expression of Insulin-Like Growth Factor Bind- ing Proteins in Bovine Kidney Epithelial Cells
}

\author{
Robert W. $\mathrm{Li}^{*}$ and Cong Jun $\mathrm{Li}$
}

\author{
Animal and Natural Resources Institute, United States Department of Agriculture, Agricultural Research Service, \\ Beltsville, MD 20705, USA
}

\begin{abstract}
Sodium butyrate induces cell cycle arrest and apoptosis in bovine kidney epithelial cells primarily via downregulating cell cycle-related gene expression and enhancing expression of pro-apoptotic genes. The insulin-like growth factor (IGF) system plays an essential role in these processes. Understanding of regulation of insulin-like growth factor binding proteins (IGFBPs) by butyrate helps reveal the mechanisms by which butyrate induces many physiological processes. In this study, we investigated effects of butyrate on the expression of insulin-like growth factors (IGF1 and IGF2), as well as their receptors (IGF1R and IGF2R) and binding proteins (IGFBPs), in Madin Darby bovine kidney (MDBK) epithelial cells. Our results demonstrated that IGF1 expression was below detection using real-time RT-PCR whereas expression of IGF2 was significantly up-regulated by butyrate in both mRNA and protein levels. Unlike IGF1R, whose expression remained unchanged, IGF2R was also up-regulated by butyrate. Butyrate significantly enhanced expression of IGFBP3 and IGFBP5, while the expression of IGFBP4 and IGFBP6 was down-regulated. Our results suggested that IGF2, not IGF1, may play a critical role in regulating cell cycle progression and programmed cell death by apoptosis in MDBK cells.
\end{abstract}

Keywords: Bovine, IGF, IGFBP, butyrate.

\section{INTRODUCTION}

As one of the natural microbial fermentation products in the gastrointestinal tract, butyrate plays a significant role in energy metabolism in ruminants [1]. Butyrate also has a multitude of cellular regulatory effects that modulate cell differentiation, proliferation, and motility primarily by acting as a histone deacetylase (HDAC) inhibitor. Our previous studies established that butyrate plays a role in inducing cell cycle arrest and apoptosis $[2,3,4,5]$. The biological endpoint of a $24 \mathrm{~h}$ treatment by $10 \mathrm{mM}$ sodium butyrate was resultant death of approximately $38 \%$ of total cells, mainly due to apoptosis [2]. In bovine kidney epithelial cells, up to $8 \%$ of all genes tested had an altered gene expression pattern resulting from butyrate treatment [4]. The butyrate-induced genes related to multiple signal pathways such as cell cycle control, extracellular matrix remodeling, and apoptosis, were discussed in details $[4,5]$.

The insulin-like growth factor (IGF) system plays an essential role in cell growth, proliferation, differentiation, transformation, and apoptosis [6]. Insulin-like growth factor binding proteins (IGFBPs) act as carrier/transport proteins in biologic fluids to control IGF efflux. In addition to their roles in prolonging IGF half-lives, IGFBPs themselves possess biological functions independent of their ability to modulate IGF activities [7]. For example, IGFBP3 has been shown to act as a ligand for nuclear receptor RXR- $\alpha$, involving in apoptosis regulation [8]. Our previous study in cattle determined that IGF2, which regulates a broad range of gene networks, is significantly up-regulated by butyrate [5].

\footnotetext{
*Address correspondence to this author at the Animal and Natural Resources Institute, United States Department of Agriculture, Agricultural Research Service, Beltsville, MD 20705, USA;

E-mail: Robert.Li@ars.usda.gov
}

Although butyrate exerts its major physiological functions in the gastrointestinal tract of ruminants, we chose bovine kidney epithelial cells (MDBK) in this study for several reasons. First, our previous studies demonstrated that MDBK cells expressed butyrate receptors and were responsive to exogenous butyrate treatment. MDBK as an established bovine cell line with inducible apoptosis and cell cycle regulatory events was also readily available. In addition, the data shown that functional type I IGF receptors were present and the cells were indeed responsive to exogenous IGF1 treatment as evidenced by resultant increase of DNA synthesis [9]. These same authors shown that MDBK cells virtually excluded any passage of IGF1 across epithelial cell monolayers; and in term of high trans-epithelial electrical resistance values, which indicated great impediment of electrolyte and macromolecular movement, MDBK cells displayed characteristics more comparable to colon carcinomas cells. In this study, we investigated how butyrate regulates expression of IGFs, IGF receptors and six IGFBPs under three cell cycle conditions: normal cell cycle where cells undergo exponential growth, cells under $72 \mathrm{~h}$ of serum deprivation ( $\sim 79 \%$ of cells are arrested in $\mathrm{G}_{1} / \mathrm{G}_{0}$ phases), and cells after $10 \mathrm{~h}$ of release from serum deprivation ( $\sim 81 \%$ of cells are in $\mathrm{S}$ phase). Our results, obtained using real-time RT-PCR and Western blot analysis, provided insights into the mechanism by which butyrate regulates cell cycle arrest and apoptosis.

\section{MATERIALS AND METHODOLOGY}

\section{Cell Culture}

The Madin-Darby bovine kidney epithelial cells (MDBK, American Type Culture Collection, Manassas, VA., Catalog No. CCL-22) were cultured in Eagle's minimal essential medium supplemented with 5\% fetal bovine serum (Invitrogen, Carlsbad, CA) in $25 \mathrm{~cm}^{2}$ flasks with medium renewal twice per week. Cell cultures were maintained in a water- 
jacked incubator with $5 \% \mathrm{CO}_{2}$ at $37^{\circ} \mathrm{C}$. Sub-cultivations were performed when cells attained 80 to $90 \%$ confluence, according to the product information supplied by American Type Culture Collection. For normal cell cycle experiment, the cells were treated with $10 \mathrm{mM}$ of sodium butyrate (Calbiochem, San Diego, CA) for $24 \mathrm{~h}$ at approximately $50 \%$ confluence (during the exponential growth phase). For the serum deprivation experiment, cells were rinsed with serumfree media and then replaced with media containing $0.5 \%$ fetal bovine serum and cultured for $72 \mathrm{~h}$. $10 \mathrm{mM}$ of sodium butyrate was then added to the media and the cells were cultured for an additional 24h. For the synchronization experiment, cells were cultured for $72 \mathrm{~h}$ in the media containing $0.5 \%$ fetal bovine serum, then released into fresh media containing 5\% fetal bovine serum for $10 \mathrm{~h}$; the released cells were then cultured at $10 \mathrm{mM}$ of sodium butyrate for additional $24 \mathrm{~h}$. Under each of the three conditions, the control was time-matched PBS. The treatment and control groups each had 3 replicates. The harvested cells were snap frozen in liquid $\mathrm{N} 2$ and stored at $-80^{\circ} \mathrm{C}$ until RNA and protein extraction.

\section{Flow Cytometry}

The detailed procedure was previously described [2, 3, 4]. Briefly, cells collected by trypsinization were washed and re-suspended in PBS. Two volumes of ice-cold 100\% ethanol were added drop-wise into tubes and mixed with cells in suspension by slow vortexing. After incubation with RNase I, cells were then stained with propidium iodide (PI). Measuring the fluorescence by flow cytometry provided a measure of the amount of PI taken up by the cells and, indirectly, the amount of DNA content, which reflects the status of cell cycle progression. Cells in $\mathrm{G}_{1} / \mathrm{G}_{0}$ phases have $2 \mathrm{C}$ DNA contents and do not undergo any DNA synthesis. Cells in $\mathrm{S}$ phase undergo rapid DNA synthesis and have DNA contents ranging from $2 \mathrm{C}$ to $4 \mathrm{C}$ whereas cells in $\mathrm{M} / \mathrm{G}_{2}$ phases have 4C DNA content again without any DNA synthesis activity. The DNA content was analyzed using a flow cytometer (FC500, Beckman Coulter, Palatine, IL) and collected data were analyzed using Cytomics RXP software (Beckman Coulter). $>10,000$ cells per sample were analyzed using flow cytometry.

\section{Preparation of Cell Extracts and Western Blot Analysis}

Preparations of cells and protein extracts, SDS-PAGE and Western Blot analysis were described previously [2, 4]. Briefly, the protein from different samples was separated by SDS PAGE on two identical 4 to $20 \%$ polyacrylamide gradient gels. One gel was stained with SimpleBlue (Invitrogen) and one was transferred to a membrane and probed with polyclonal anti-IGF2R (Novus Biologicals, Littleon, CO, USA) and anti-IGFBP2 (Abcam, Inc., Cambridge, MA, US, which also cross-reacts with IGFBP1) antibodies. The relative densities of the target bands on the Western Blots from three experiments were quantified with image software UNSCAN-IT (Silk Scientific, Orem, Utah, USA). The data were then statistically analyzed using one-way analysis of variance (ANOVA).

\section{Real-Time RT-PCR}

Total RNA was extracted as previously described [4]. Briefly, total RNA was first extracted using Trizol (Invitrogen) followed by DNase digestion and purification using an RNeasy Mini kit (Qiagen, Valenica, CA). RNA integrity was verified using a Bioanalyzer 1000 (Agilent, Palo Alto, CA).

Real-time RT-PCR analysis was carried out using the iQ SYBR Green Supermix kit (Biorad) with $200 \mathrm{nM}$ of each amplification primer (Table 1) and the $1^{\text {st }}$-strand cDNA (100 ng of the input total RNA equivalents) in a $25 \mu 1$ reaction volume. The amplification was carried out on an iCycler $\mathrm{iQ}^{\mathrm{TM}}$ Real Time PCR Detection System (BioRad) with the following profile: $95^{\circ} \mathrm{C}-60 \mathrm{~s} ; 40$ cycles of $94^{\circ} \mathrm{C}-15 \mathrm{~s}, 60^{\circ} \mathrm{C}-30 \mathrm{~s}$, and $72^{\circ} \mathrm{C}-30 \mathrm{~s}$. The melting curve analysis was performed for each primer pair. Expression levels of $\beta$-actin remained constant and were used as endogenous controls. Relative gene expression data were calculated using the $2^{-\Delta \Delta C T}$ method [10]. The data were then analyzed using unpaired Student's $t$-test with $P<0.05$ being taken as significant.

\section{RESULTS}

\section{Butyrate Induces Cell Cycle Arrest and Apoptosis Inde- pendent of Cell Cycle Status}

In our previous study [2, 4], we monitored butyrate induced cell death and cell cycle arrest in MDBK cells in a time/dose-dependent manner using flow cytometry and

Table 1. Primers Used in Real-Time RT-PCR

\begin{tabular}{|c|c|l|l|}
\hline Gene & GenBank Accession\# & \multicolumn{1}{|c|}{ Forward Primer } & \multicolumn{1}{c|}{ Reverse Primer } \\
\hline \hline IGF1 & NM_001077828 & ACAGGAATCGTGGATGAG & ACTCCCTCTACTTGTGTTC \\
\hline IGF2 & NM_174087 & CGCTCAGAGAGGCCAAGAGT & GGCTCACTTCTAATCGCTGGAT \\
\hline IGF1R & XM_606794 & TGACGAGAGACATCTATGAGAC & GACCCCGAAGGACCAGAC \\
\hline IGF2R & NM_174352 & TGCCTCCCGAGTCAGTAAC & AATCTTTGGGTGGGTTGTTTG \\
\hline IGFBP1 & NM_174554 & TTTTTCAAGTGGTTCAATGGAG & CAACATTTAAGTTTCCCTGCC \\
\hline IGFBP2 & NM_174555 & AGCACCTCTACTCCCTACAC & GTTCACACACCAGCACTCC \\
\hline IGFBP3 & NM_174556 & AATCGCCCTTGCTTGGTG & GGTCGTGGCTGTGTTTATATTC \\
\hline IGFBP4 & NM_174557 & CTGAGACCCAATCCCAACAC & TCTCCATCAGGCACATACATTC \\
\hline IGFBP5 & XM_600908 & CACACTGACAACCCCAAATCTG & GCCTGAAGGTCCAGCATCC \\
\hline IGFBP6 & NM_001040495 & AAGGAGAGTAAGCCCCAAGCA & CGGGAAGGAGTGGTAGAGGTC \\
\hline
\end{tabular}


Western blotting. The cell population profiles were investigated under three experimental conditions at a single selected dose that was proven to be capable of generating maximum biological impact. First, under the normal cell cycle condition, the exponentially growing cells consist of approximately $41 \%$ of $\mathrm{G}_{1} / \mathrm{G}_{0}$ cells and $49 \%$ of $\mathrm{S}$ phase cells (Table 2). As previously reported, butyrate induced cell cycle arrest and drastic changes in cell population profiles in MDBK cells [4]. A significant increase in the number of cells in $\mathrm{G}_{1}$ phase (with $2 \mathrm{C}$ DNA contents) and decrease in $\mathrm{S}$ phase cells (falling between the $2 \mathrm{C}$ and $4 \mathrm{C}$ DNA contents) was observed (Fig. 1), suggesting the cells were indeed arrested at the $\mathrm{G}_{1} / \mathrm{S}$ boundary and that DNA replication was blocked by butyrate treatment. Under serum deprivation condition, the cell population was predominantly at the $\mathrm{G}_{1} / \mathrm{G}_{0}$ phases ( $\left.\sim 79 \%\right)$. However, when released from serum deprivation for $10 \mathrm{~h}$, synchronization occurred and $\sim 81 \%$ of the cell population was shifted to $S$ phase (Table 2). Under all three conditions, sodium butyrate induced cell cycle arrest and cell death as identified by TUNEL assay [2], suggesting the anti-proliferative and pro-apoptotic effects of butyrate were independent of cell cycle status. Accumulation of acetylated histone $3(\mathrm{H} 3)$ was also observed under all three conditions (data not shown), indicating that the biological effects of butyrate in these cells were due to its histone deacetylase inhibitory activity.

Table 2. Flow Cytometric Assessment of the Cell Population*

\begin{tabular}{|c|c|c|c|}
\hline & $\mathbf{\%}_{\mathbf{1}} / \mathbf{G}_{\mathbf{0}}$ & $\mathbf{\%} \mathbf{S}$ & $\mathbf{\%} \mathbf{M} / \mathbf{G}_{\mathbf{2}}$ \\
\hline \hline Normal cell cycle (N) & $41.4 \pm 1.5$ & $48.7 \pm 1.8$ & $9.9 \pm 0.4$ \\
\hline Serum Deprivation (G) & $79.4 \pm 1.0^{* *}$ & $12.3 \pm 0.8 * *$ & $8.3 \pm 0.6$ \\
\hline Release (S) & $15.8 \pm 1.9^{* *}$ & $80.6 \pm 3.4 * *$ & $3.6 \pm 3.5$ \\
\hline
\end{tabular}

*Data represent Mean \pm SEM of 4 separate experiments.

$* * P<0.01$ based on one way ANOVA.

$\mathrm{N}=$ Cells in normal cell cycle.

$\mathrm{G}=$ Cells after serum deprivation (predominantly in $\mathrm{G}_{1} / \mathrm{G}_{0}$ phase).

$\mathrm{S}=$ Cells after serum deprivation and release (predominantly in $\mathrm{S}$ phase).

\section{Real-Time RT-PCR}

Gene expression of IGFs, IGF receptors, and six IGF binding proteins regulated by butyrate was monitored under three experimental conditions using real-time RT-PCR. The expression of IGF1 under all three conditions was below detection after 40 cycles of amplification, regardless of butyrate treatment (Table 3). The butyrate treatment induced significant $(P<0.05)$ up-regulation of IGF2 under these conditions (143 to 363 fold). In the control group, serum deprivation (S) and release (G) alone induced IGF2 mRNA upregulation $\sim 5$ fold compared to control cells under normal cell cycle.

Insulin-like growth factor 1 receptor (IGF1R) expression was detectable and remained constant under all three conditions. Butyrate induced slightly down-regulation of IGF1R. However, the changes were not significant. In contrast to IGF1R, IGF2R expression was enhanced by butyrate under all three conditions 4-10 fold. Butyrate induced upregulation of IGF2R more in the $\mathrm{G}_{1} / \mathrm{G}_{0}$ phase dominated cell population than in the cell populations of predominantly S phases (Table 3).

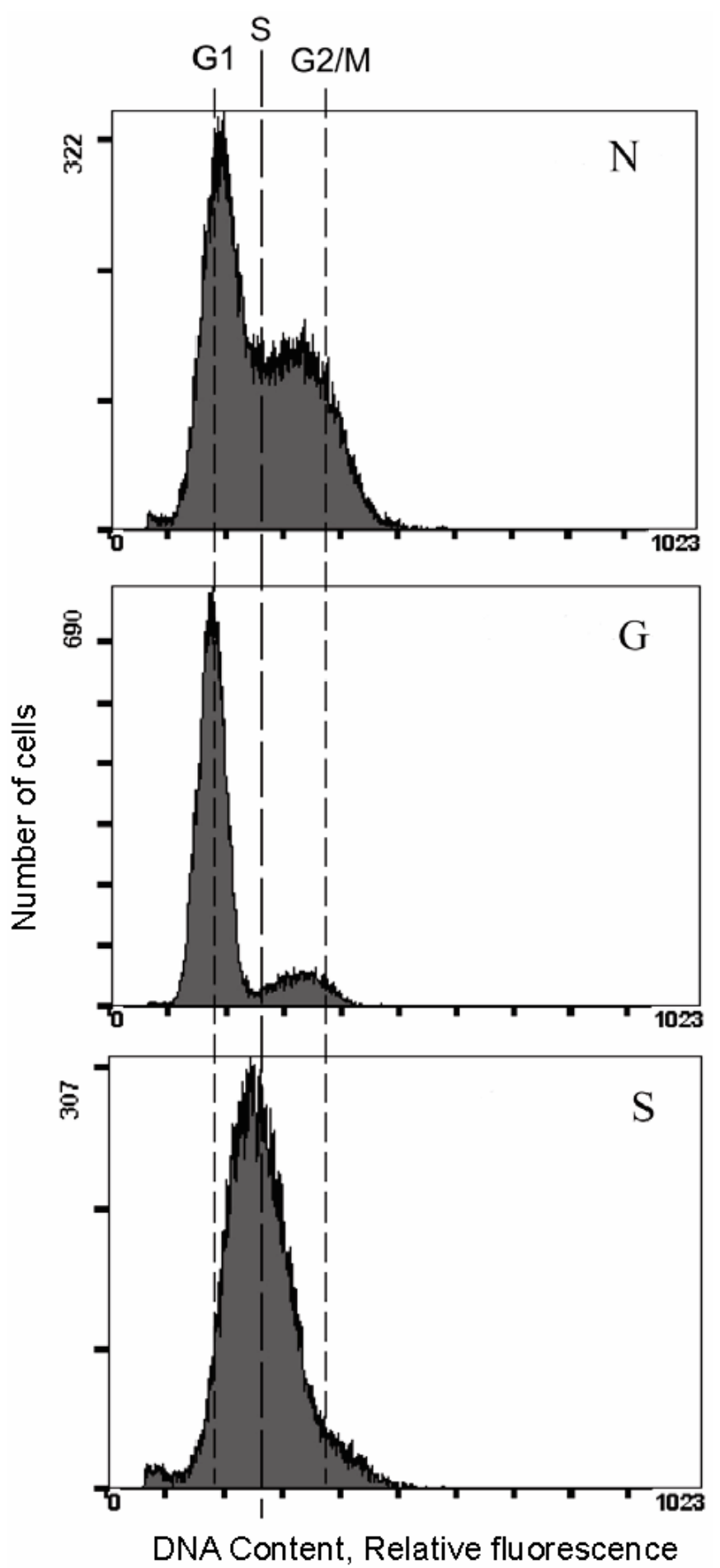

Fig. (1). Cell population profiles determined by flow cytometry. Histogram plots of flow cytometry analysis of MDBK cells under three experimental conditions were displayed: N: cells with normal cell cycle; G: cells after $72 \mathrm{~h}$ serum deprivation; and $\mathrm{S}$ : cells released for $10 \mathrm{~h}$ after $72 \mathrm{~h}$ of serum deprivation. Deconvolution of the DNA histogram using Cylchred software. Data represent means from three replicates. $G_{1}$ : cells in $G_{1} / G_{0}$ phases; $S$ : cells in $S$ phase; $\mathrm{G}_{2} / \mathrm{M}$ : cells in $\mathrm{M} / \mathrm{G} 2$ cell cycle phases.

Butyrate regulated all insulin-like growth factor binding proteins (IGFBPs) except IGFBP2 in bovine kidney epithelial cells. Butyrate up-regulated IGFBP3 and IGFBP5 whereas IGFBP4 and IGFBP6 were down-regulated slightly 
(Table 3). IGFBP3 was significantly up-regulated by butyrate under all three conditions (14-24 fold).

Table 3. Gene Expression Induced by Sodium Butyrate Under Three Experimental Conditions Measured Using Real-Time RT-PCR

\begin{tabular}{|c|c|c|c|c|c|c|}
\hline \multirow{2}{*}{} & \multicolumn{6}{|c|}{ Treatment (Mean Fold; n=3) } \\
\cline { 2 - 7 } & N+CT & S+CT & G+CT & N+SB & S+SB & G+SB \\
\hline \hline IGF1 & BD & BD & BD & BD & BD & BD \\
\hline IGF2 & 1.0 & 4.6 & $4.7^{*}$ & $143.4^{*}$ & $298.5^{*}$ & $363.0^{*}$ \\
\hline IGF1R & 1.0 & 1.0 & 1.2 & 0.9 & 0.8 & 0.9 \\
\hline IGF2R & 1.0 & 0.9 & 1.4 & $4.7^{* *}$ & $4.5^{*}$ & 10.7 \\
\hline IGFBP1 & 1.0 & 0.6 & 1.6 & 5.1 & 1.9 & 5.9 \\
\hline IGFBP2 & 1.0 & 0.9 & 0.9 & 1.8 & 0.6 & 0.9 \\
\hline IGFBP3 & 1.0 & 1.2 & 1.4 & $21.2^{*}$ & $14.6^{* *}$ & $23.9^{*}$ \\
\hline IGFBP4 & 1.0 & 1.0 & 1.0 & $0.3^{* *}$ & $0.3^{*}$ & $0.2^{* *}$ \\
\hline IGFBP5 & 1.0 & 0.9 & 1.2 & 2.3 & $2.3^{*}$ & $3.5^{*}$ \\
\hline IGFBP6 & 1.0 & 1.1 & 1.3 & 0.7 & $0.5^{* *}$ & $0.4^{*}$ \\
\hline
\end{tabular}

$\mathrm{N}=$ Cells in normal cell cycle; $\mathrm{S}=$ Cells after serum deprivation and release (predominantly in S phase); $G=$ Cells after serum deprivation (predominantly in $\mathrm{G}_{1} / \mathrm{G}_{0}$ phase). $\mathrm{CT}=$ control; $\mathrm{SB}=$ treated with sodium butyrate at $10 \mathrm{mM}$ for $24 \mathrm{~h} . \mathrm{BD}=$ below detection after 40 cycles. In the control group (CT), the two cell-cycle stages (S and G) were compared to normal $(\mathrm{N})$, respectively. In the treatment group, SB treatment was compared to the untreated control in their respective cell cycle stages (for example, $\mathrm{G}+\mathrm{SB}$ vs $\mathrm{G}+\mathrm{CT}) . *=P<0.05 ; * *=P<0.01$.

\section{Western Blot Analysis}

Due to availability of antibodies that recognize bovine proteins, only a limited number of proteins were analyzed using Western blot analysis. Overall trends indicated that there was a good correlation between mRNA expression and protein expression. The parallel expression was evident for all proteins analyzed in this system. As Fig. (2) shows, SB induced IGF2R expression in protein level under all three conditions. However, a greater induction of IGF2R was achieved when the population was predominantly $G_{1} / G_{0}$ phase cells $(G)$, in an agreement with the mRNA results measured by real-time RT-PCR (Table 3). Also consistent with the mRNA results, IGFBP2 protein was not significantly altered by butyrate.

\section{DISCUSSION}

Insulin-like growth factors (IGF) play a pivotal role in regulating cell proliferation and differentiation as a potent mitogen. They are also a critical modulator of cellular growth and transformation in many tissues [6]. IGF1 acts in a paracrine and endocrine manner to affect bovine mammary gland development [11]. In addition, IGFs are capable of inhibiting programmed cell death by apoptosis in various cell types [12]. Although IGFs exert their biological functions through their receptors for signal transduction, the biological activities of IGFs are regulated by their binding proteins. The four major functions of IGFBPs have been documented [7]: acting as carrier proteins in biological fluids with very high affinity binding to both IGF1 and IGF2 to ensure virtually all circulating IGFs are bound to IGFBPs; prolonging IGF half-
(A)

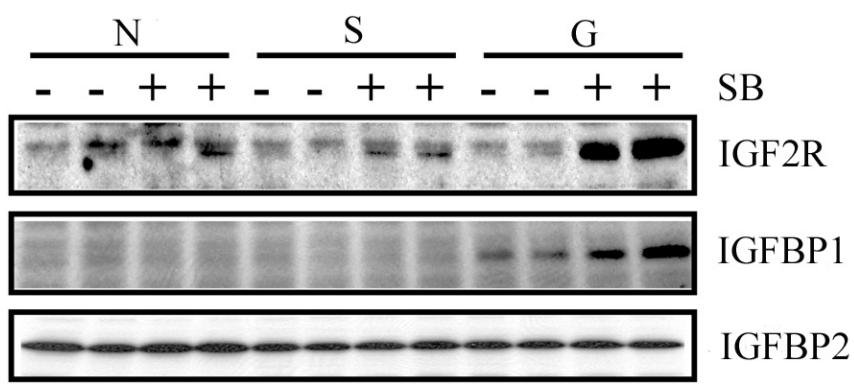

(B)

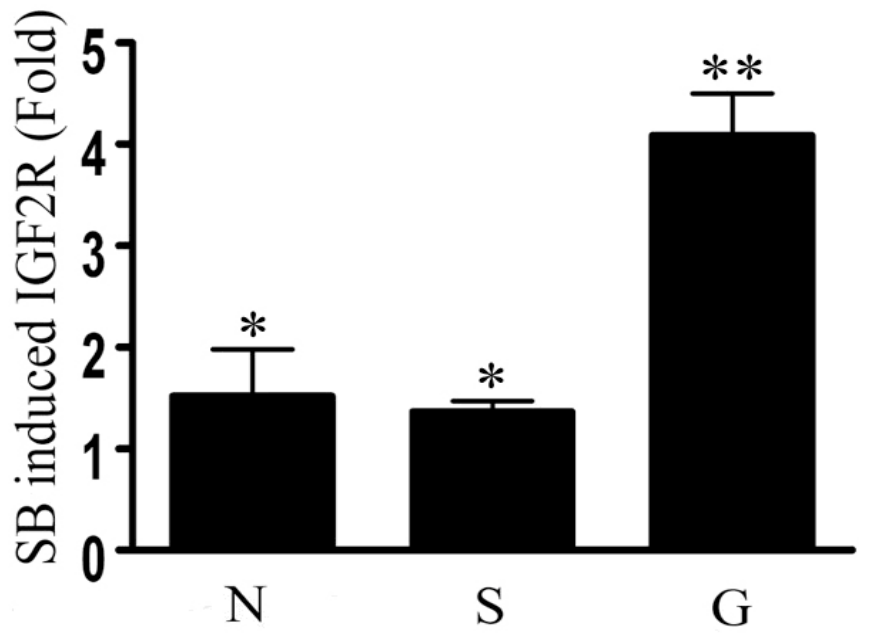

Fig. (2). Western blot analysis of IGF2R, IGFBP1, and IGFBP2 under three experimental conditions. N: cells with normal cell cycle; G: cells after $72 \mathrm{~h}$ serum deprivation; and S: cells released for $10 \mathrm{~h}$ after serum deprivation. SB: sodium butyrate treatment at $10 \mathrm{mM}$ for $24 \mathrm{~h}$. (A) Protein from different samples was separated by SDS PAGE on 4 to $20 \%$ polyacrylamide gradient gels. The gel was transferred to a membrane for Western blotting with polyclonal anti-IGF2R and anti-IGFBP2 antibodies. The samples were loaded in duplicate. (B) Butyrate-induced fold change of IGF2R protein. Western Blots from three experiments were quantified using UNSCAN-IT image software. Polyclonal anti-IGFBP2 antibody recognizes both IGFBP1 and IGFBP2. $*=P<0.05 ; * *=P<0.01$. Data are presented as means $\pm \mathrm{SEM}$.

lives; providing a mean of tissue- and cell type-specific localization; and modulating interaction of IGFs with their receptors. Most recently, IGFBPs have been found to have direct biological functions that are independent of IGFs [13, 14]

In this study, we systematically investigated the expression regulation of the IGF system by butyrate in bovine cells. Our results indicated that IGF1 was below detection and IGF1R remained non-responsive to butyrate treatment. The observation of strong up-regulation of both IGF2 and IGF2R by butyrate suggested that IGF2 may play a more important role in bovine kidney epithelial cells in vitro, even though in many systems, most of the actions of both IGF1 and IGF2 are mediated by the IGF1R [7]. This is also in sharp contrast to murine mammary glands where IGF1 was always expressed at significantly higher levels than either IGF2 or IGFR and plays a more important role during mammary 
morphogenesis $[15,16]$. Indeed, mRNA expression of IGF2 and IGF2R was significantly induced by butyrate under all three conditions, resulting in a parallel increase in IGF2R protein level (Fig. 2A). As an imprinted gene in cattle and canines, IGF2R recognizes multiple ligands such as IGF2, retinoic acid [17], and TGF $\beta$, having a broad range of physiological functions including its association with tumorigenesis [18] and apoptosis. IGF2R is generally regarded as a negative regulator of IGF2 by acting as a sink. However, it has been shown that over-expression of soluble IGF2R leads to an increase in IGF2 levels in vivo [19]. It is possible that over-expression of IGF2R induced by butyrate in MDBK cells is involved in pro-apoptotic processes. Therefore, understanding actions of IGF2R in IGF signaling pathway in MDBK cells becomes intriguing.

Among six IGFBPs, it seemed that as the predominant IGFBP secreted [20], IGFBP2 was not regulated by butyrate in both mRNA and protein levels in MDBK cells. Both IGFBP4 and IGFBP6 were down-regulated by butyrate. Down-regulation of IGFBP6 observed in this study also confirmed our previous findings using microarrays [4]. IGFBP6 has a 100-fold higher affinity for IGF2 than for IGF1 [21]. This seemingly paradoxical observation, that while IGF2 expression is strongly up-regulated by $\mathrm{SB}$, its highest affinity binding protein is down-regulated, suggested that different functions of various IGFBP members modulated IGF signaling transduction. Butyrate up-regulated IGFBP3, and IGFBP5; and, specifically, IGFBP3 expression was increased 14 to 24 fold by butyrate in our observation. It has been demonstrated that IGFBP3 induces apoptosis in an IGF-independent manner through the activation of caspases involving a death receptor-mediated pathway in human breast cancer cells [22]. Besides increased cleavage of caspases 7 and 8, IGFBP 3 is also capable of increasing the ratio of pro-apoptotic Bax and Bad to anti-apoptotic Bcl-2 and $\mathrm{Bcl}-\mathrm{X}_{\mathrm{L}}$ proteins [23]. Our observation also suggested that butyrate induced up-regulation of CDKN1A (p21) was mediated by IGFBP 3 to achieved its inhibitory effect on cell proliferation and cell cycle. It has been documented that butyrate and other HDAC inhibitors increase IGFBP3 expression by activating the IGFBP3 promoter via an Sp1/Sp3 multiprotein complex formed on the butyrate responsive element in the promoter region [13]. IGFBP5 is a negative regulator of IGF1 [24]. In mouse mammary epithelial cells, IGFBP5 expression is increased during apoptosis induced by TGF $\beta-3$ treatment along with a parallel increase of cleaved apoptotic marker caspase 3 [25]. The causal relationship between IGFBP5 and apoptosis was documented in transgenic mice expressing IGFBP5 $[26,27]$ and the effects of IGFBP5 may be mediated in part by IGF-independent effects involving potential interactions with the extracellular matrix system (ECM). The biological significance of IGFBP5-ECM association has been carefully examined [28]. Indeed, our previous network analysis identified a complex network of genes involving IGF2, matrix metallo-proteinases (MMP1 \& MMP13), TIMP3, connective tissue growth factor and IGFBPs that are regulated by butyrate in MDBK cells [5]. Although butyrate up-regulated both IGFBP3 and IGFBP5 in this study, our in silico analysis suggested the promoter regions of these two bovine genes shared few structural similarities. There exist multiple $\mathrm{Sp} 1$ sites within a $70 \mathrm{bp}$ region upstream from the transcription start site (TSS) in bovine
IGFBP3. However, unlike its human counterpart [13], the stretch of $11 \mathrm{p} 53$ consensus binding sites is absent in bovine IGFBP3. The TATA box does not appear in the IGFBP5 promoter region. While $\mathrm{Sp} 1$ and $\mathrm{AP}-1$ sites exist, a single p53 binding site is located 11 bp downstream of TSS in bovine IGFBP5. Therefore, different kinds of transcriptional machinery may be involved in transcriptional regulation of both genes by butyrate. Together, these studies suggested that IGFBP3 and IGFBP5 may play an essential role in regulating butyrate-inducing cell death. Our future work will include comparing the expression profiles induced by both butyrate and exogenous IGFBPs and siRNA to IGFBPs in apoptotic pathway regulation in MDBK cells. Dissecting the mechanism of butyrate in regulating genes associated with cell death by apoptosis, cell proliferation and differentiation will not only facilitate designing more potent HDAC inhibitors for cancer but also help to understand ruminant physiology, which in turn could lead to improvement in energy utilization efficiency of cattle.

\section{CONCLUSION}

In this study, we systematically investigated the expression regulation of the IGF system by sodium butyrate using both real-time RT-PCR and Western blot analysis in bovine kidney epithelial cells under three experimental conditions: cells under normal cell cycle progression, cells after serum deprivation, and cells after release from serum deprivation. Our results suggested that IGF2, not IGF1, may play an essential role in regulating cell cycle progression and programmed cell death by apoptosis; and over-expression of IGF2R induced by butyrate may be involved in pro-apoptotic processes in MDBK cells. While the functions of IGFBPs seemed diverse, IGFBP3 and IGFBP5 were shown to be a primary regulator of butyrate-induced cell growth arrest and apoptosis. Because butyrate functions as both a nutrient and signaling molecule in ruminants, our findings enable better understanding of biological functions of short-chain fatty acids such as butyrate, during cattle energy metabolism, cell growth and proliferation.

\section{ACKNOWLEDGEMENTS}

The authors thank Joy Castano for her excellent technical assistance. Mention of trade names or commercial products in this publication is solely for the purpose of providing specific information and does not imply recommendation or endorsement by the U. S. Department of Agriculture.

\section{REFERENCES}

[1] Sharp WM, Johnson RR, Owens FN. Ruminal VFA production with steers fed whole or ground corn grain. J Anim Sci 1982; 55: 1505-1514.

[2] Li CJ, Elsasser TH. Butyrate-induced apoptosis and cell cycle arrest in bovine kidney epithelial cells: involvement of caspase and proteasome pathways. J Anim Sci 2005; 83: 89-97.

[3] Li CJ, Elsasser TH. Specific cell cycle synchronization with butyrate and cell cycle analysis by flow cytometry for Madin Darby bovine kidney (MDBK) cell line. J Anim Vet Adv 2006; 5: 916923.

[4] Li RW, Li CJ. Butyrate induces profound changes in gene expression related to multiple signal pathways in bovine kidney epithelial cells. BMC Genomics 2006; 7: 234.

[5] Li CJ, Li RW, Wang YH, et al. Pathway analysis identifies perturbation of genetic networks induced by butyrate in a bovine kidney epithelial cell line. Funct Integr Genomics 2007; 7: 193-205. 
[6] Stewart CE, Rotwein P. Growth, differentiation, and survival: multiple physiological functions for insulin-like growth factors. Physiol Rev 1996; 76: 1005-1026.

[7] Jones JI, Clemmons DR. Insulin-like growth factors and their binding proteins: biological actions. Endocr Rev 1995; 16: 3-34.

[8] Liu B, Lee HY, Weinzimer SA, et al. Direct functional interactions between insulin-like growth factor-binding protein-3 and retinoid $\mathrm{X}$ receptor-alpha regulate transcriptional signaling and apoptosis. J Biol Chem 2000; 275: 33607-33613.

[9] Bastian SE, Walton PE, Ballard FJ, et al. Transport of IGF-I across epithelial cell monolayers. J Endocrinol 1999; 162: 361-369.

[10] Livak KJ, Schmittgen TD. Analysis of relative gene expression data using real-time quantitative PCR and the $2^{-\triangle \Delta C T}$ Method. Methods 2001; 25: 402-408.

[11] Plath-Gabler A, Gabler C, Sinowatz F, et al. The expression of the IGF family and GH receptor in the bovine mammary gland. J Endocrinol 2001; 168: 39-48.

[12] Sell C, Baserga R, Rubin R. Insulin-like growth factor I (IGF-I) and the IGF-I receptor prevent etoposide-induced apoptosis. Cancer Res 1995; 55: 303-306.

[13] Walker GE, Wilson EM, Powell D, et al. Butyrate, a histone deacetylase inhibitor, activates the human IGF binding protein-3 promoter in breast cancer cells: molecular mechanism involves an Sp1/Sp3 multiprotein complex. Endocrinology 2001; 142: 38173827.

[14] Collard TJ, Guy M, Butt AJ, et al. Transcriptional upregulation of the insulin-like growth factor binding protein IGFBP-3 by sodium butyrate increases IGF-independent apoptosis in human colonic adenoma-derived epithelial cells. Carcinogenesis 2003; 24: 393401.

[15] Boutinaud M, Shand JH, Park MA, et al. A quantitative RT-PCR study of the mRNA expression profile of the IGF axis during mammary gland development. J Mol Endocrinol 2004; 33: 195207.

[16] Flint DJ, Tonner E, Allan GJ. Insulin-like growth factor binding proteins: IGF-dependent and -independent effects in the mammary gland. J Mammary Gland Biol Neoplasia 2000; 5: 65-73.

[17] Kang JX, Bell J, Leaf A, et al. Retinoic acid alters the intracellular trafficking of the mannose-6-phosphate/insulin-like growth factor II receptor and lysosomal enzymes. Proc Natl Acad Sci USA 1998; 95: 13687-13691.
[18] DaCosta SA, Schumaker LM, Ellis MJ. Mannose 6-phosphate/insulin-like growth factor 2 receptor, a bona fide tumor suppressor gene or just a promising candidate? J Mammary Gland Biol Neoplasia 2000; 5: 85-94.

[19] Zaina S, Newton RV, Paul MR, et al. Local reduction of organ size in transgenic mice expressing a soluble insulin-like growth factor II/mannose-6-phosphate receptor. Endocrinology 1998; 139: 38863895.

[20] Cohick WS, Clemmons DR. Regulation of insulin-like growth factor binding protein synthesis and secretion in a bovine epithelial cell line. Endocrinology 1991; 129: 1347-1354.

[21] Baxter RC, Saunders H. Radioimmunoassay of insulin-like growth factor-binding protein- 6 in human serum and other body fluids. J Endocrinol 1992; 134: 133-139.

[22] Kim HS, Ingermann AR, Tsubaki J, et al. Insulin-like growth factor-binding protein 3 induces caspase-dependent apoptosis through a death receptor-mediated pathway in MCF-7 human breast cancer cells. Cancer Res 2004; 64: 2229-2237.

[23] Butt AJ, Firth SM, King MA, et al. Insulin-like growth factorbinding protein-3 modulates expression of Bax and Bcl-2 and potentiates p53-independent radiation-induced apoptosis in human breast cancer cells. J Biol Chem 2000; 275: 39174-39181.

[24] Tonner E, Allan G, Shkreta L, et al. Insulin-like growth factor binding protein-5 (IGFBP-5) potentially regulates programmed cell death and plasminogen activation in the mammary gland. Adv Exp Med Biol 2000; 480: 45-53.

[25] Lochrie JD, Phillips K, Tonner E, et al. Insulin-like growth factor binding protein (IGFBP)-5 is upregulated during both differentiation and apoptosis in primary cultures of mouse mammary epithelial cells. J Cell Physiol 2006; 207: 471-479.

[26] Flint DJ, Boutinaud M, Tonner E, et al. Insulin-like growth factor binding proteins initiate cell death and extracellular matrix remodeling in the mammary gland. Domest Anim Endocrinol 2005; 29: 274-282.

[27] Tonner E, Barber MC, Allan GJ, et al. Insulin-like growth factor binding protein-5 (IGFBP-5) induces premature cell death in the mammary glands of transgenic mice. Development 2002; 129: 4547-4557.

[28] Beattie J, Allan GJ, Lochrie JD, et al. Insulin-like growth factorbinding protein-5 (IGFBP-5): a critical member of the IGF axis. Biochem J 2006; 395: 1-19. 